\title{
The use of an online learning management system by postgraduate nursing students at a selected higher educational institution in KwaZulu-Natal, South Africa
}

\author{
L I Buthelezi, M Nursing Education; J M van Wyk, PhD \\ Department of Clinical and Professional Practice, Nelson R Mandela School of Medicine, University of KwaZulu-Natal, Durban, South Africa
}

Corresponding author: JM van Wyk (vanwykj2@ukzn.ac.za)

Background. The use of information and communications technology (ICT) in nursing education is a key strategy following the impact of COVID-19 on higher education institutions. It highlights the need for efficient learning management systems and meta-capabilities of graduates. Studies have described e-learning at the undergraduate level, while less is known about learning management systems (LMS) use among postgraduate nurses.

Objectives. To explore students' perceptions of e-learning, their perceived challenges with technology on a compulsory postgraduate nursing module and associations between demographic data and listed challenges.

Methods. An exploratory quantitative study used a self-administered questionnaire to collect data from all postgraduate students $(N=60)$. Data included demographics, language proficiency, prior training, computer access at home, frequency of use, prior exposure to e-learning platforms, attitude to technology, perceived computer self-efficacy, and anxiety and attitude towards computer use for learning. Statistical analysis included using frequency distributions, $\chi^{2}$ and Pearson's test to measure and explore associations between challenges and sociodemographic factors.

Results. The cohort consisted of mainly black (95\%) and female (75\%) students. They expressed positive views about technology usage. Seventy percent reported first-time exposure to the Moodle learning management system at the university, and $68.3 \%$ had access to a computer. The majority (66.7\%) expressed having limited ICT skills and difficulty using Moodle. Statistically significant associations were found between the ability to use Moodle and proficiency in English, computer literacy, availability of technical support and access to computers.

Conclusion. E-learning has the potential to yield positive outcomes for continued professional learning. Students should be proficient in English, and require early introduction, training and technical support to use Moodle effectively.

Afr J Health Professions Educ 2020;12(4):211-214. https://doi.org/10.7196/AJHPE.2020.v12i4.1391

The use of information and communications technology (ICT) and e-learning in health professions and nursing education has been thrust into the limelight as the most suitable option for learning in the wake of the global and devastating COVID-19 pandemic. Apart from the focus on professional-level disciplinary skills, the greater use of learning management systems (LMS) for e-learning offers an opportunity to reflect on metacapabilities required of graduates to function effectively as lifelong learners in the social and working environments of the 21st century. These metacapabilities include self-regulation of learning, knowledge construction and synthesis, adaptability, creativity, information management, critical thinking and digital competence. ${ }^{[1]}$ While e-learning is believed to be an attractive option to meet the growing demand for education in countries with teacher shortages, ${ }^{[2]}$ it is equally important that adult users understand the benefits of digital literacy skills ${ }^{[3]}$ and strive to become suitably skilled to use the more flexible learning modalities for lifelong and continued professional

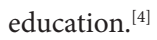

E-learning refers to the use of technology to advance teaching, learning and assessment. ${ }^{[5]}$ The use of ICT for education is widely believed to support social transformation, and it is viewed as a viable option to improve the skill sets of citizens of the country. ${ }^{[5,6]}$ The National Plan for Higher Education in South Africa $(\mathrm{SA})^{[7]}$ encourages institutions to develop information societies through technology use and advancements to create new platforms for active learning, and thus improve education. A 2015 study, however, reported that despite the national policies to promote equitable access to ICT to previously disadvantaged people, ${ }^{[7]}$ higher education institutions (HEIs) lacked a common strategy for the rollout of e-learning, and that there were variable use of and access to ICT across SA institutions. ${ }^{[5,8]}$ One of the national strategies was the proposal for ICT and curriculum departments to form stronger collaborations and synergies to advance the use of e-learning in $\mathrm{SA},{ }^{[9]}$ as reports suggested that HEIs in SA had no common approach or strategy.

The issue of unfamiliarity with technological advances has been described in high-income countries. ${ }^{[10]}$ Much less is known about student readiness for digital learning in low- and middle-income countries. All HEIs are obliged to provide the necessary policy, infrastructure, support and training to facilitate students' use of learning management systems (LMS), of which the one used at the current institution is Moodle. It is therefore important that students receive the necessary training and technical support in using Moodle for learning to help them experience the benefits of online learning.

The technology acceptance model (TAM) provides a possible framework to understand the relationship between humans and technology by focusing on the perceived usefulness and perceived ease of use in technology for learning. ${ }^{[11]}$ According to the TAM, users' beliefs influence their attitudes, and resilience towards a new technology and an assessment of their attitude can be used to predict the actual use of the technology.

The nursing department at the institution offers a module in communitybased education every alternative Thursday in an online format via the platform. The facilitator posts the objectives for the session weekly on the discussion forum. She then encourages students to respond to questions 
posed during the session. She continues to interact with each student who has responded to the questions, and asks clarifying and follow-up questions until task completion. While this process is communicated to students before they access the course online, and despite training and orientation, students become frustrated with the system. Some common complaints are an inability to log onto the LMS, difficulty in sending emails, and basic insecurities about the best way to solve their online learning problems. Given the changing educational landscape and greater demand for students (including postgraduate (PG) students) to make use of available information technologies, it became necessary to explore students' engagement with e-learning, and the use of the e-learning platform (Moodle) at a selected higher education institution within KwaZulu-Natal (KZN) Province, SA. The specific objectives of the study were to:

(i) explore PG nursing students' perceptions of the use of an e-learning platform

(ii) explore PG nursing students' perceived challenges regarding the use of e-learning platforms

(iii) explore demographic factors of PG nursing students that are associated with their use of the e-learning platform.

\section{Methodology \\ Research design}

An exploratory quantitative study was conducted using a questionnaire ${ }^{[12]}$ to collect the views of PG nursing students about their access to, and familiarity and experiences with, the LMS on one campus at a SA HEI that offers a nursing qualification in KZN.

A purposive convenience sampling strategy was used to invite all eligible PG students $(N=60)$ to complete a self-reported questionnaire that was only available in English. Respondents included all students who were enrolled in a compulsory core module of the Master's of Nursing qualification.

\section{Data collection process}

Ethical approval for the study was obtained from the University of KZN Ethics Committee (ref. no. HSS/1718/016M), and gatekeepers' permission was obtained from the Dean of the School of Nursing and Public Health, and the head of the nursing department. The self-reported questionnaire was modified ${ }^{[13,14]}$ and piloted with 10 final-year undergraduate students to establish the content validity of the questionnaire. The questionnaire explored latent variables of attitude towards technology, perceived computer self-efficacy, computer anxiety and attitude towards using computersupported education.

Section A of the questionnaire explored mainly demographic data - race, age, gender, home language, LMS training, computer access at home, and frequency of use and exposure to e-learning platforms before registering on the module. Section B presented a set of 26 statements where respondents had to use a four-item Likert scale with 1 representing 'strongly agree' and 4 representing 'strongly disagree' to indicate their level of agreement with various statements relating to the Moodle LMS. The first author met with the students and lecturers and negotiated a date for data collection. She then attended the class at a pre-arranged time to explain the purpose of the study, answer questions, assure respondents that their contributions would be anonymous and explain that they could participate or withdraw if they wished to do so.

\section{Data analysis and presentation}

SPSS version 24.0 (IBM Corp., USA), was used to organise and analyse the raw quantitative data. Descriptive statistics that described one variable at a time were used: mean, unvaried standard deviation, contingency tables, correlation indexes and the frequencies of two or more variables were cross-tabulated. Measures of central tendency were used to describe data (mode, mean, median), and the relationships between variables were established using correlational procedures. Statistical analysis included using frequency distributions and a $\chi^{2}$ test to measure associations between challenges and sociodemographic factors. Pearson's test was used to explore the nature of associations between sociodemographic variables and challenges regarding the use of e-learning.

\section{Results \\ Descriptive statistics}

The biographical details of the cohort are reported in Table 1 .

\section{Analytical statistics}

Students' perceptions regarding Moodle use

In response to the objective that explored students' perceptions regarding Moodle use, students used a Likert scale to indicate their level of agreement to each statement (Appendix: http://ajhpe.org.za/public/files/1391.pdf).

The results showed that $62.1 \%(n=36)$ of participants had undergone training before accessing the Moodle platform, while 37.9\% ( $n=22)$ had not received training. A total of $68.3 \%(n=41)$ respondents reported having access to a computer at home, while $31.7 \%(n=19)$ did not have home access and therefore used a computer on campus. Seventy percent $(n=42)$ of respondents had no prior exposure to online learning platforms before enrolling on the course, as opposed to $30.0 \%(n=18)$ who reported prior online learning experience. When asked about their knowledge of using computers, 57 responses were received. Twenty-eight percent $(n=16)$ agreed, and $5.3 \%(n=3)$ strongly agreed that they had limited computer knowledge.

\section{Overall score relating to perception of Moodle use}

An overall score of the students' perception of the use of Moodle was calculated on the first 13 items. The responses ranged from $1=$ strongly

Table 1. Summary of sociodemographic characteristics

\begin{tabular}{lll}
\hline Characteristic & Variable & $\boldsymbol{n}(\%)$ \\
\hline Race $(n=59)$ & African & $56(94.9)$ \\
& White & $2(3.4)$ \\
& Coloured & $1(1.7)$ \\
Age group $(n=57)$ & & \\
& $21-30$ years & $21(36.8)$ \\
& $31-40$ years & $20(35.1)$ \\
& $41-50$ years & $15(26.3)$ \\
Gender $(n=57)$ & $51-60$ years & $1(1.8)$ \\
& & \\
Proficient in reading English $(n=58)$ & Male & $14(24.5)$ \\
& Female & $43(75.4)$ \\
& Yes & $56(96.5)$ \\
& No & $2(3.4)$
\end{tabular}




\begin{tabular}{|c|c|c|}
\hline Demographic factor & Perceptions and challenges & $p$-value \\
\hline Age & If I make an error, I find it difficult to recover from it. & 0.03 \\
\hline Age & I find it difficult to adapt to this culture of learning. & 0.039 \\
\hline English proficiency & I feel that Moodle is easy to use. & 0.020 \\
\hline English proficiency & I feel I need to use technical support to use Moodle. & 0.040 \\
\hline English proficiency & I feel that Moodle is a flexible learning management software. & 0.001 \\
\hline English proficiency & I feel that Moodle has a simple and natural dialogue. & 0.037 \\
\hline English proficiency & Overall, I am satisfied with how easy it is to use Moodle. & 0.000 \\
\hline English proficiency & The information provided on Moodle is easy to understand. & 0.000 \\
\hline English proficiency & While using Moodle, it is easy to read characters on the screen. & 0.005 \\
\hline English proficiency & I feel that the organisation of information in Moodle is clear. & 0.000 \\
\hline English proficiency & I learned to use Moodle quickly. & 0.024 \\
\hline Duration of training & I feel that the organisation of information in Moodle is clear. & 0.043 \\
\hline Accessibility of a computer & I feel I need to use technical support to use Moodle. & 0.018 \\
\hline Accessibility of a computer & I feel that Moodle is a flexible learning management software. & 0.008 \\
\hline Accessibility of a computer & I learned to use Moodle quickly. & 0.024 \\
\hline Accessibility of a computer & I can explore features of Moodle by trial and error. & 0.001 \\
\hline Accessibility of a computer & The information provided on Moodle is easy to understand. & 0.025 \\
\hline Exposure to online learning platforms before registration & When using Moodle, I need to remember a lot of information. & 0.021 \\
\hline
\end{tabular}

disagree, $2=$ disagree, $3=$ agree, to $4=$ strongly agree. A higher score indicated a more positive perception of the use of Moodle. The minimum score was 24 , and the maximum score was 47 . The mean was 37.30 , and the standard deviation was 5.148. The median and the mode were 37 . Overall, an average of $50 \%$ of respondents had a score of 37 , which indicated a positive perception of the use of Moodle.

\section{Challenges regarding the use of e-learning}

The findings relating to students' challenges associated with using the LMS were based on 57 responses. A collective $24.5 \%$ of the respondents strongly agreed $(n=4)$ and agreed $(n=10)$ to experiencing difficulty with navigating the programme after having been away from Moodle for a few days. A total of $58 \%$ of respondents agreed $(n=21)$ and strongly agreed $(n=11)$ with the item regarding the need for technical support when being introduced to Moodle, while $42 \%$ collectively disagreed $(n=16)$ and strongly disagreed $(n=8)$ with the need for technical support to use Moodle effectively. Three students did not answer this item.

The majority of the respondents in this study, 54.5\% $(n=30)$, were comfortable using Moodle: 32.7 percent $(n=18)$ strongly agreed that they were comfortable, $7.3 \%(n=4)$ disagreed, and $5.5 \%(n=3)$ strongly disagreed with the statement. In the present study, 38.6\% $(n=22)$ of respondents agreed that they felt at ease using Moodle, 33.3\% ( $n=19)$ strongly agreed that this was the case, $22.8 \%(n=13)$ disagreed with the statement, and $5.3 \%$ $(n=3)$ strongly disagreed. This study also showed that out of 57 respondents, $61.4 \%(n=35)$ agreed that the organisation of information on Moodle was clear, and $22.8 \%(n=13)$ strongly agreed that it was clear, while $14.0 \%(n=8)$ disagreed and $1.8 \%(n=1)$ strongly disagreed. Out of 54 respondents, $57.4 \%$ $(n=31)$ disagreed with the statement that they found it difficult to recover after having made errors when using Moodle, and 18.5\% ( $n=10)$ strongly disagreed; $16.7 \%(n=9)$ and $7.4 \%(n=4)$ agreed.

\section{Student challenges with Moodle use}

Concerning the objective that investigated students' challenges with Moodle use, a Pearson $\chi^{2}$ test was used to explore associations between sociodemographic variables and the items related to the challenges regarding the use of e-learning. An association was found between the following: age and making errors $\left(\chi^{2}=13.407, \mathrm{df}=6, p=0.03\right)$; age and finding it difficult to adapt to the culture of learning $\left(\chi^{2}=17.675, \mathrm{df}=9, p=0.039\right)$; proficiency in English and learning to use Moodle quickly $\left(\chi^{2}=9.420, \mathrm{df}=3, p=0.024\right)$; access to computers and learning to use Moodle quickly $\left(\chi^{2}=9.41 ; \mathrm{df}=3\right.$; $p=0.024)$; access to a computer and exploring features of Moodle by trial and error $\left(\chi^{2}=17.120 ; \mathrm{df}=3 ; p=0.001\right)$; exposure to online learning platforms before registration and the need to remember a lot of information when using Moodle $\left(\chi^{2}=9.695 ; \mathrm{df}=3 ; p=0.021\right)$.

The majority of participants viewed Moodle as a flexible LMS. The study, however, did find an association with proficiency in English and accessibility to computers. English proficiency was associated with the following challenges: ease of reading; students' perception that content was well-structured; and ease of Moodle use. Those who indicated that the LMS was user-friendly were also more proficient in English.

\section{Discussion}

This study investigated the use of e-learning platforms by PG nursing students, specifically their perceptions of and perceived challenges in engaging on Moodle as an LMS. As indicated by the demographic and age profile (Table 1), the cohort was a representative sample of PG students who typically enrol in the Master's in Nursing degree at the institution. While $93.3 \%$ of the class indicated that they were proficient in English, it is disconcerting that four students who classified themselves as not proficient enrolled in the programme despite being aware of the requirement for English proficiency. English is the official medium of instruction at the institution. 
Many students agreed with the statement that they found the use of Moodle relatively easy. While Lwoga ${ }^{[8]}$ recommends the need for technical support for students who experience difficulty with online learning, Chipps et al. $\mathrm{s}^{[15]}$ study strongly recommended that technical support be provided to all students, including those who re-entered a HEI after having been part of the workforce for many years. They argued that students from the latter categories were more used to traditional methods of teaching and in greater need of support. Only 7\% of the current cohort reported this as a challenge.

In this cohort, students received training and technical support in the use of Moodle at the start and during the online course. The department of Information Communication Technology provided technical support, and staff from the library provided training to access databases and online journals. We did, however, find a significant association between students' perception of ease of use and their proficiency in English.

Although most of the students experienced Moodle as a good LMS, the results indicate a significant association between age and familiarity with technology. This finding means that older students generally faced greater challenges in accessing and using the Moodle platform to support their learning. It is possible that older students lacked a proper understanding of the value of Moodle as the LMS. The limited use of the LMS was likely to support those learners who were intimidated by the online learning format. That older students are 'digital strangers' has been confirmed by various authors, ${ }^{[15-17]}$ whose findings also report the need for technical support for students less familiar with ICT.

This study also found some associations to highlight. These include accessibility of a computer and learning to use Moodle quickly, general accessibility of a computer and exploration of features in Moodle by trial and error. Secondly, associations were found between exposure to online learning platforms before registration and the perception that one needs to remember a lot of information when using Moodle. Thirdly, this study found an association between student age and making errors, age and difficulty in adapting to the culture of learning, as well as proficiency in English and learning to use Moodle quickly. These results relating to age as a barrier are similar to studies that reported age and lack of knowledge as barriers to the successful use of technology. ${ }^{[18]}$

\section{Study limitations}

This questionnaire was administered only to students in one module of a Master's programme at one institution; therefore, the results are not generalisable to other modules or institutions. A mixed methodology study would have enhanced the findings and provided richer insight and exploration into issues that had been highlighted in the survey. However, the findings will contribute to greater insight into challenges and possible solutions for PG students who return to study after a prolonged period away from HEIs.

\section{Conclusion}

The study produced information that can help to promote a healthy culture of use of e-learning in HEIs. The knowledge can be used to inform curriculum development to integrate ICT into the teaching and learning process at PG level and to assist PG nursing students to access the online platform for specific reasons such as continued professional development.

\section{Declaration. None.}

Acknowledgements. The authors would like to acknowledge the PG nursing students who participated in this project. We extend our appreciation to Dr B Tlou for statistical assistance, and Dr A Smith from the Department of Nursing and Public Health and Dr B Keke from the School of Life Sciences for their support and guidance during the design phase.

Author contributions. LB contributed to the conception, design, development and execution while JV assisted in manuscript preparation.

Funding. None.

Conflicts of interest. None.

1. Plomp T. Educational design research: An introduction to educational design research. In: Plomp T, Nieveen N, eds. An Introduction to Educational Design Research. Enschede: Netherlands Institute for Curriculum Development 2013:9-36. 2. United Nations Educational, Scientific and Cultural Organization Institute for Statistics. Teachers and educational quality: Monitoring global needs for 2015. Paris: UNESCO IFS, 2006. http://uis.unesco.org/sites/default/files/ documents/teachers-and-educational-quality-monitoring-global-needs-for-2015-en_0.pdf (accessed 7 June 2020)

3. Schreurs KA, Quan-Haase A, Martin K. Problematizing the digital literacy paradox in the context of older adults ICT use: Aging, media discourse, and self-determination. Canadian J Communication 2017;42(2). https://doi org/10.22230/cjc.2017v42n2a3130

4. Bichsel J. The state of e-learning in higher education: An eye toward growth and increased access. EDUCAUSE, 2013. https://library.educause.edu/ /media/files/library/2013/6/ers1304.pdf?la=en (accessed 30 September 2020).

5. Bagarukayo E. Social media use to transfer knowledge into practice and aid interaction in higher education. Int J Educ Dev Using ICT 2018;14(2):211-232. https://www.learntechlib.org/p/184689/article_184689.pdf (accessed 30 September 2020).

6. Jaffer SD, Ngambi L, Czerniewicz L. The role of ICTs in higher education in South Africa: One strategy for addressing teaching and learning challenges. Int J Educ Dev Using ICT 2007;3(4):131-142. https://www.learntechlib. addressing teaching and learning challenges. Int J Educ Dev
org/p/42220/article_42220.pdf (accessed 20 May 2020).

7. Bagarukayo E, Kalema B. Evaluation of elearning usage in South African universities: A critical review. Int J Educ Bagarukayo E, Kalema B. Evaluation of elearning usage in South African universities: A critical review. Int J Educ
Dev Using ICT 2015;11(2):168-183. https://www.learntechlib.org/p/151848/article_151848.pdf. (accessed 30 September 2020)

8. Lwoga ET. Critical success factors for adoption of web-based learning management systems in Tanzania. Int J Educ Dev Using ICT 2014;10(1):4-21. https://www.learntechlib.org/p/147447/article_147447.pdf (accessed 30 September 2020).

9. Lwoga ET. Integrating Web 2.0 into an academic library in Tanzania. Electronic Library 2014;32(2):183-202. http:/ www.academia.edu/download/36781072/final_electronic_lib_archiving.pdf (accessed 30 September 2020).

10. Bridgstock R. Educating for digital futures: What the learning strategies of digital media professionals can teach higher education. Inno Educ Teach Int 2016;53(3):306-315. https://doi.org/10.1080/14703297.2014.956779

11. Al-Busaidi KA, Al-Shihi H. Instructors' acceptance of learning management systems: A theoretical framework. Communications of the IBIMA 2010. 2010(2010):1-10. http://ibimapublishing.com/articles/ framework. Communications of the IBIMA 2010. 2010(2010).

12. Polit DF, Beck CT. Nursing Research: Generating and Assessing Evidence for Nursing Practice. Philadelphia: Lippincott Williams \& Wilkins, 2008

13. Celik V, Yesilyurt E. Attitudes to technology, perceived computers self-efficacy and computer anxiety as predictors of computers of computer supported education. Computers Edu 2013;60(1);148-158. https://doi.org/10.1016/j. compedu. 2012.06 .008

14. Daneshmandnia A. A usability study of Moodle. Proceedings of the Spring 2013 Mid-Atlantic Section Conference of the American Society of Engineering Education. https://www.asee.org/papers-and-publications/papers/sectionproceedings/middle-atlantic/ASEE-Middle-Atlantic-Spring-2013-Proceedings.pdf (accessed 12 November 2020).

15. Chipps J, Kerr J, Brysiewicz P, Walters F. A survey of university students' perceptions of learning management systems in a low-resource setting using a technology acceptance model Computers Informatics Nursing systes:33(2):71-77. 2015,33(2):11 Perceptions

16. Czerniewicz L, Brown C. The habitus of digital 'strangers' in higher education. Br J Educ Tech 2013;44(1):44-53. https://doi.org/10.1111/j.1467-8535.2012.01281.x

17. Queiros D, de Villiers M. Online learning in a South African higher education institution: Determining the right connections for the student. Int Rev Res Open Distributed Learning 2016;17(5):165-185. https:// www.erudit.org/en/journals/irrodl/1900-v1-n1-irrodl04876/1064710ar.pdf (accessed 30 September 2020).

18. Porter $\mathrm{CE}$, Donthu $\mathrm{N}$. Using the technology acceptance model to explain how attitudes determine internet usage: The role of perceived access barriers and demographics. J Business Res 2006;59(9):999-1007. http://www.academia. edu/download/52477167/using_technology_acceptance (accessed 30 September 2020).

Accepted 27 July 2020. 